$\underline{\text { Avicenna Journal of Nursing and Midwifery Care - ISSN 2676-5748 }}$

\title{
The Effect of Group Reminiscence on Loneliness in Iranian Elderly
}

\author{
Faiza Gholami Shilsar', Mohammad Esmaeilpour-Bandboni2 ${ }^{*}$, Atefeh Basharkhah ${ }^{1}$
}

1. Master of Nursing, Department of Nursing, Guilan University of Medical Sciences, Rasht, Iran

2. PhD in Nursing, Department of Nursing, Guilan University of Medical Sciences, Rasht, Iran

\begin{tabular}{ll}
\hline Article Info & ABSTRACT \\
\hline
\end{tabular}

Received: 2020/02/15

Accepted: 2020/04/26;

Published Online: 2020/10/01

10.30699/ajnmc.29.1.35

Original Article

Use your device to scan and read the article online

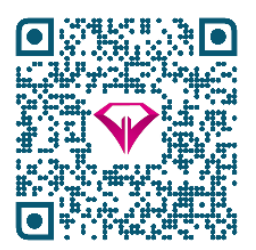

Introduction: Deprivation of social activities increases the feeling of loneliness among older adults. Reminiscence as the recall of past events, feelings, and thoughts, is one of the nursing interventions in nursing homes. This study aimed to determine the influence of group reminiscence on loneliness of older adults those living in hospitals affiliated with Guilan University of Medical Sciences in 2019.

Methods: In this quasi-experimental study, 32 older who met the inclusion criteria were randomly selected and entered in two groups, intervention and control group. Both groups completed a standard questionnaire as pre-test. After that, intervention group participated in a reminiscence protocol. The schedule was carried out twice a week, eight times and each season last 1 to 1.5 hours.

Results: There was no significant difference in loneliness between the intervention and control groups before the intervention. Loneliness $(P=0.0001)$ was significantly lower in the reminiscence group compared with the control group.

Conclusion: As a dynamic and interactive method, group-based memory recalling can reduce the feeling of loneliness in the elderly.

Keywords: Reminiscence, Loneliness, Elderly, Nursing

Copyright $\odot$ 2021, This is an original open-access article distributed under the terms of the Creative Commons Attribution-noncommercial 4.0 International License which permits copy and redistribution of the material just in noncommercial usages with proper citation.

\section{How to Cite This Article:}

Gholami Shilsar F, Esmaeilpour-Bandboni M, Basharkhah A. The Effect of Group Reminiscence on Loneliness in Iranian Elderly. Avicenna J Nurs Midwifery Care. 2020; 29 (1) :35-44 


\section{بررسى تأثير خاطرهزويى گروهى بر ميزان احساس تنهايى سالمندان ايرانى}

فايزه غلامى شيلسر'، محمد اسماعيل يور بندبنى ب*، عاطفه بشرخواه'

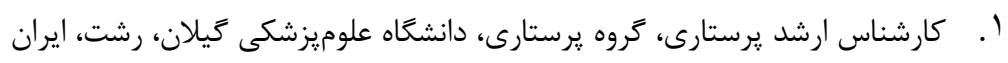

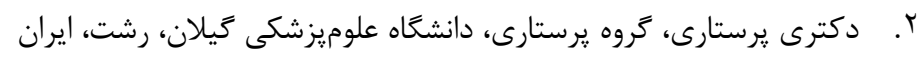

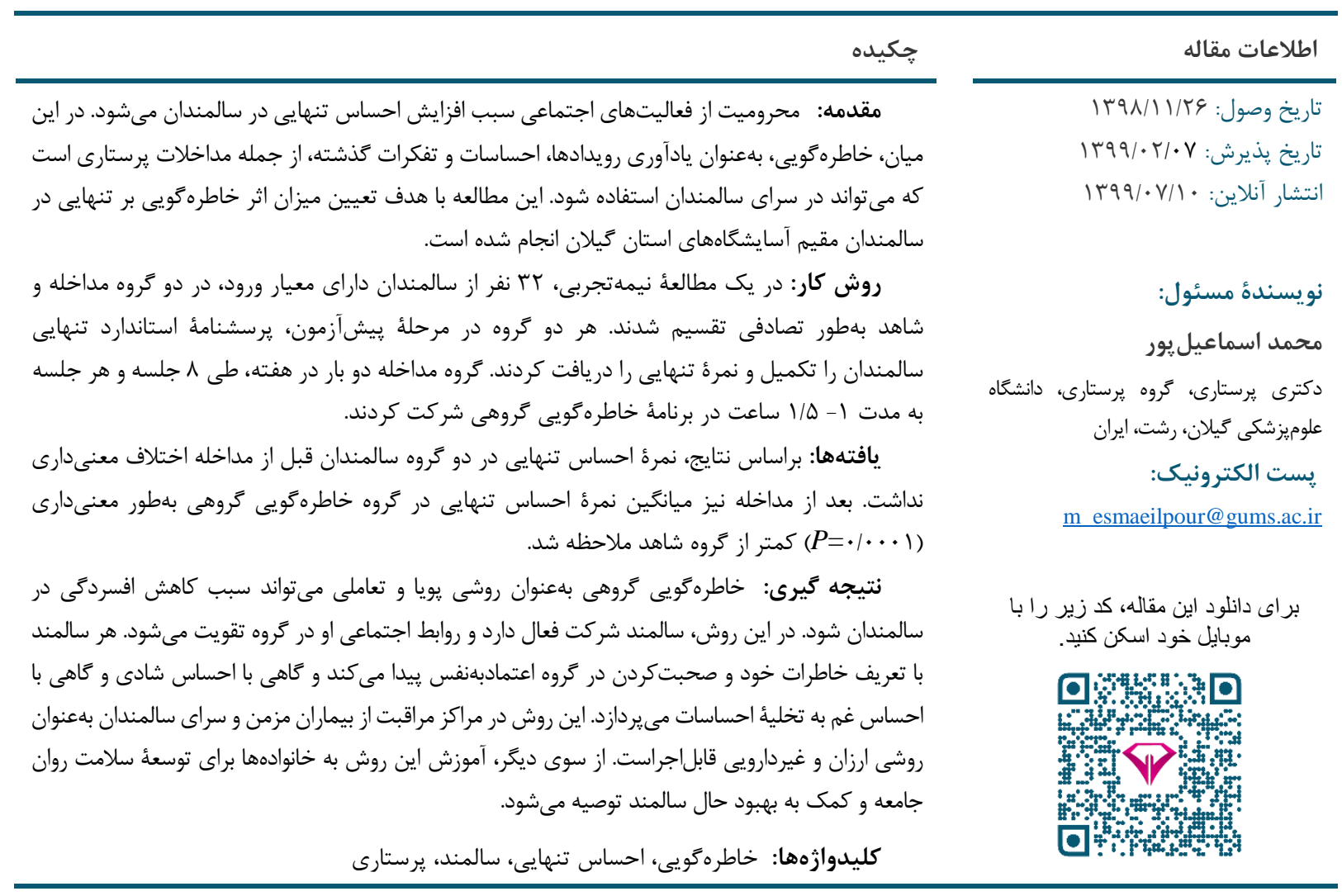

براساس آمارهاى سازمان جهانى بهداشت، در سال . . . . حدود 9. .

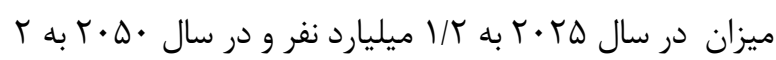

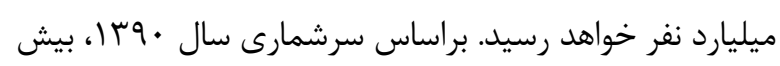

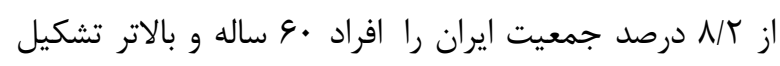

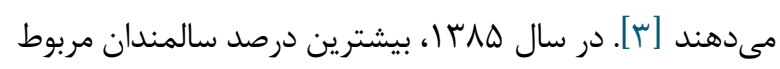
به استانهاى گيلان، خراسان جنوبى، سمنان و مركزى بوده

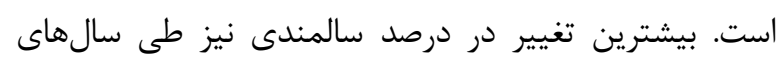

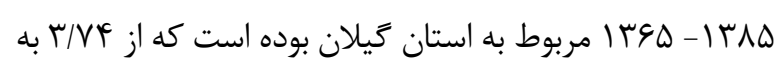

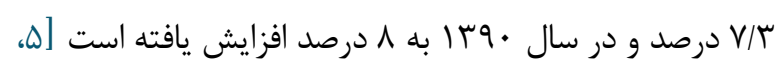

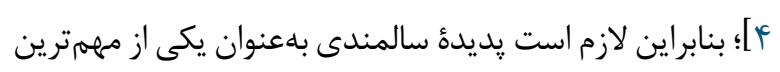

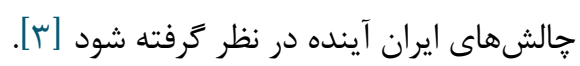

سالمندى يعنى تغييرات زيستشناختى مشترك براى تمام

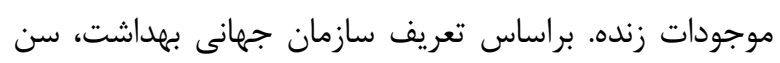
سالمندى از •و سال و بالاتر تعريف شده است [1 [1]. تركيب

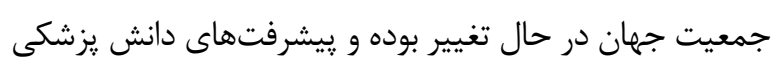

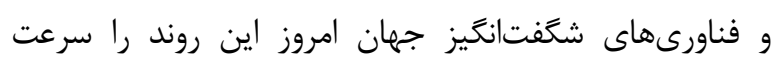

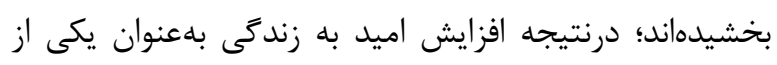

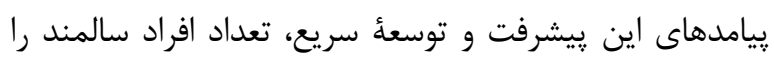

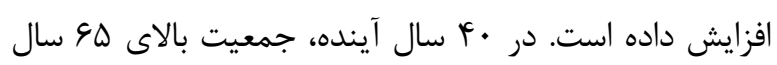

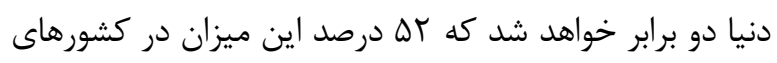

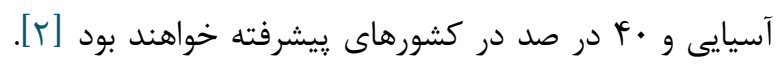

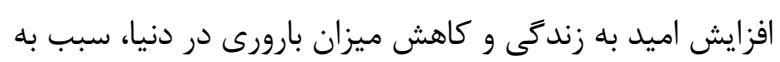
وجود آمدن گيديده سالمندى در جهان و و ايران شده است. 
احساس تنهايى و افسردگى سالمندان تايوانى را بررسى كردند

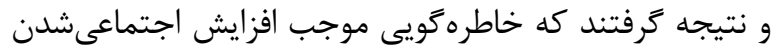

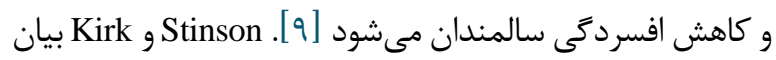

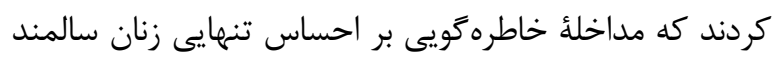

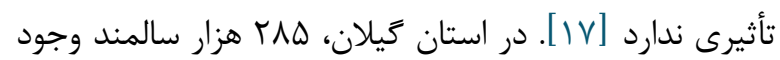

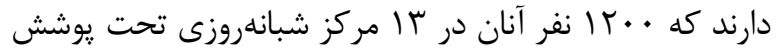

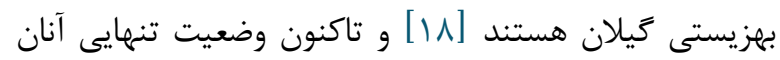

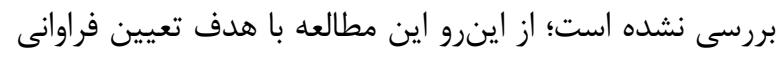

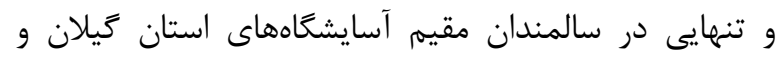

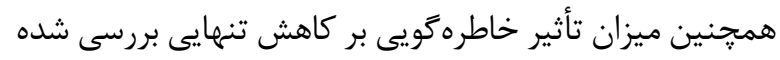

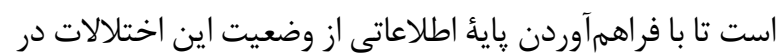
سالمندان كيلان، از صرف هزينههاى اضافى بيمار كاسته شود.

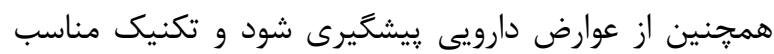
غيردارويى در حرفهٔ يرستارى ارتقا يابد.

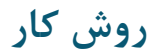

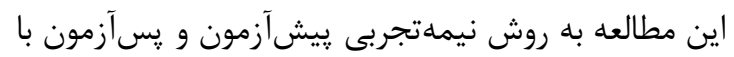

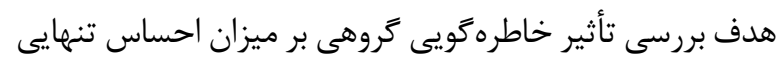

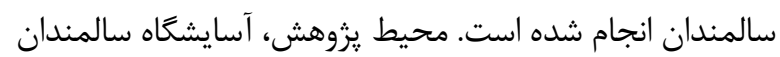

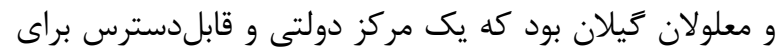

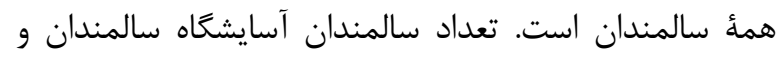

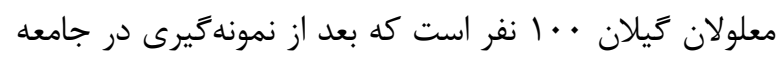

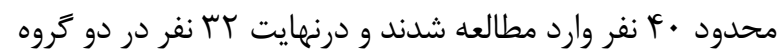

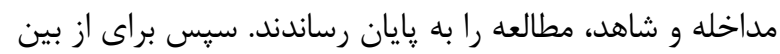

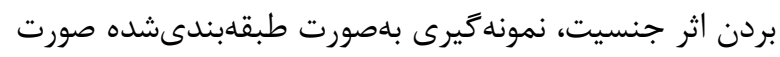

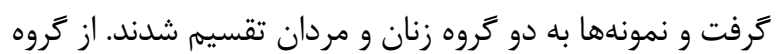

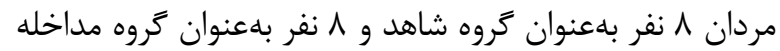

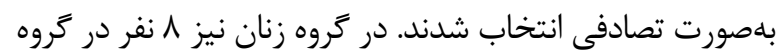

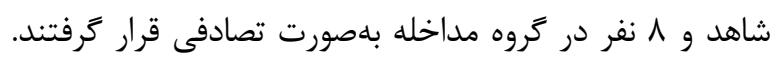
جهت تصادفىسازى از جدول اعداد استفاده شد.

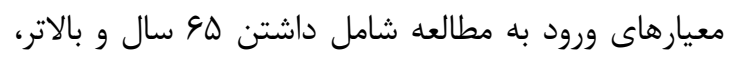
زندگى تماموقت در آسايشگاه، تمايل به شركت در در تحقيق،

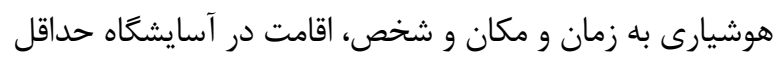
به مدت شش ماه بود. معيارهاى خروج از مطالعه نيز عبارت بار بود

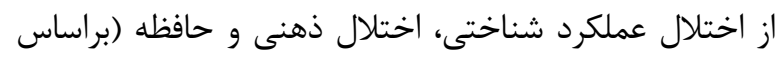

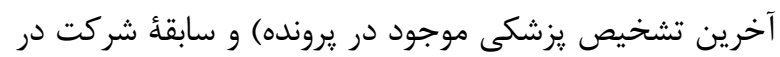

با افزايش سن، افراد بهتدريج برخى كاركردهاى فيزيولوزيك و روانى -اجتماعى خود را از دست مي دهند؛ درنتيجه محروميت بنديت

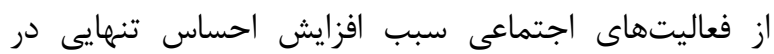
سالمندان مىشود [ع]. احساس تنهايى تجربهاى ناخوشايند و

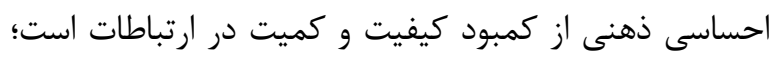

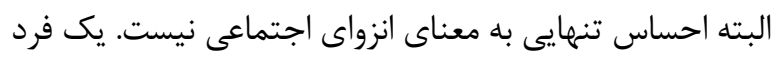

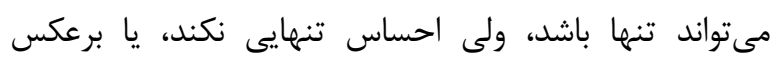

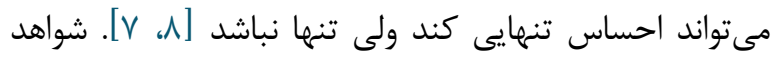

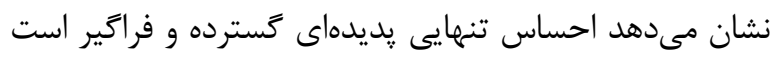

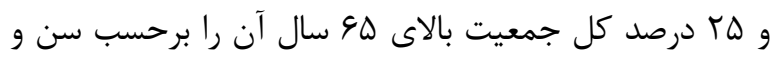

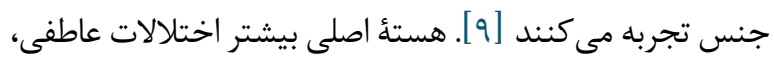
احساس انزوا و تنهايى است؛ بنابراين از ميان مسائل سالمندان

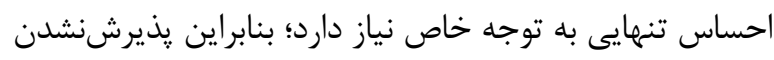

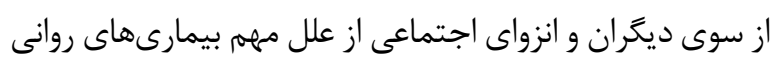
در سنين سالمندى به شمار مى آيد [ [ [1].

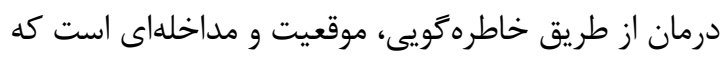

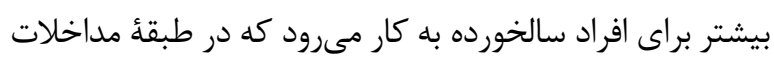

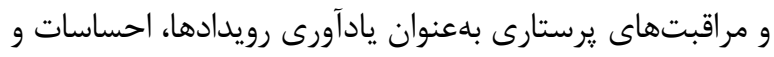

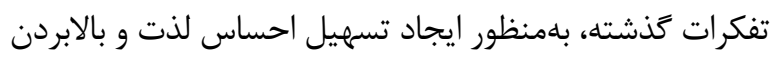

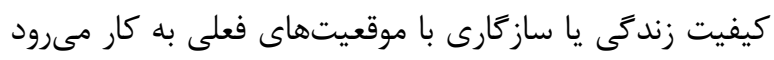

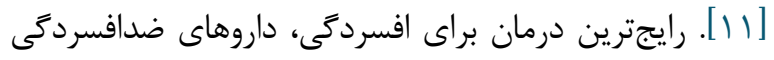

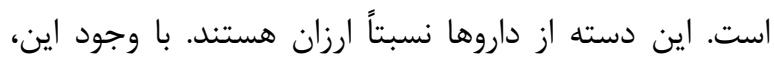

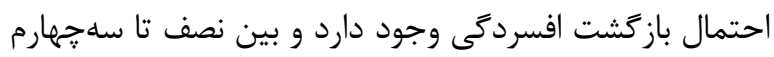

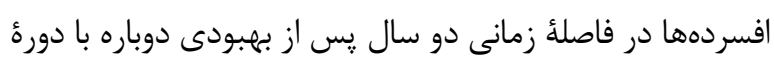

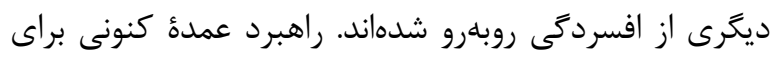

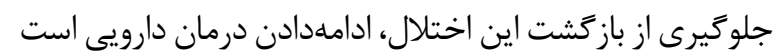

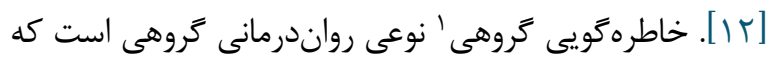

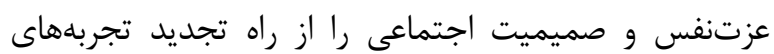

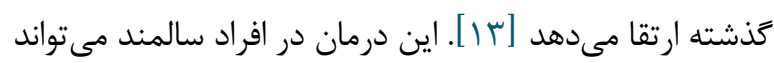

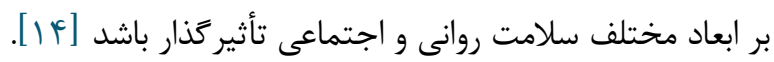

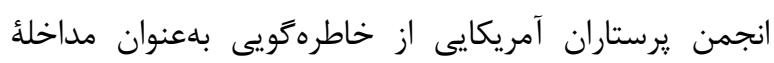

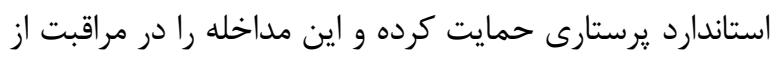

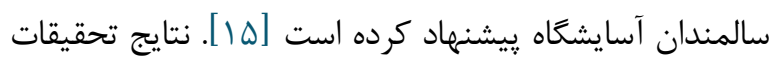
Mokel ،Shellman آمريكايى نشان مى دهد، خاطرهو إيى مىتواند دليلى بر كاهش

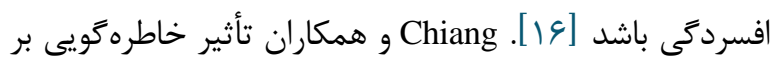


^r بررسى تأثير خاطرهوَيى كروهى بر ميزان احساس تنهايى سالمندان ايرانى

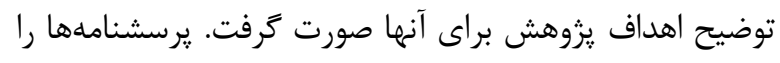

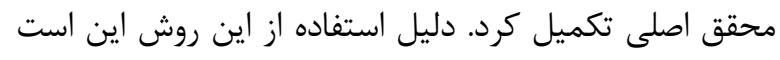

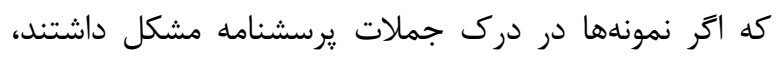

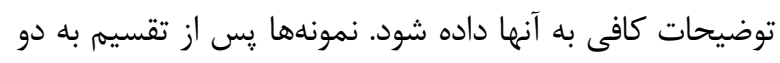

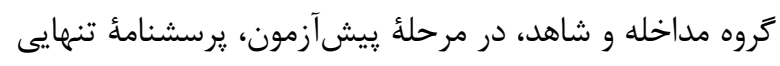

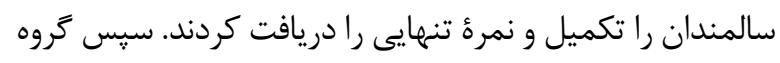

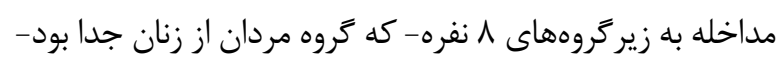

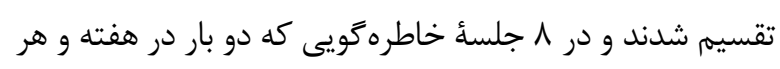

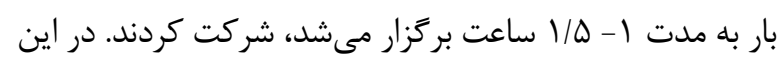

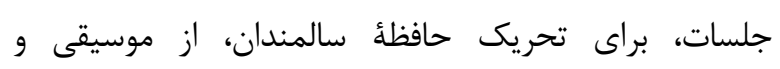
عكسهاى قديمى در قالب بستر فرهنگى استان كيلان استفاده

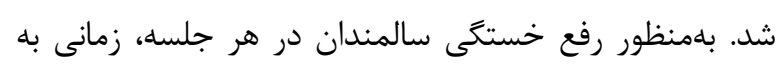

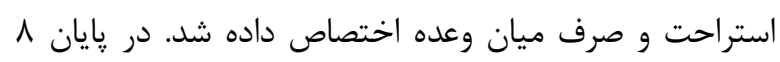

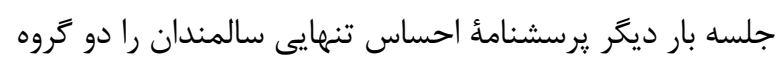

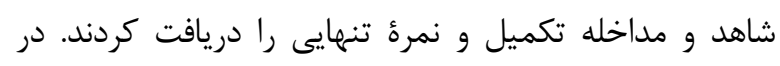
جدول ا، محتواى جلسات خاطرهويى بيان شده است.
جلسات خاطرهويى. ابزار اين مطالعه از دو بخش دموَرافيك

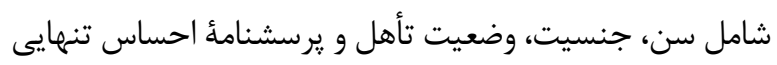

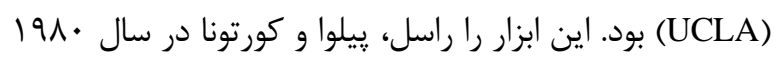

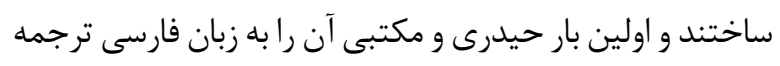

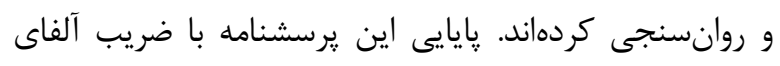

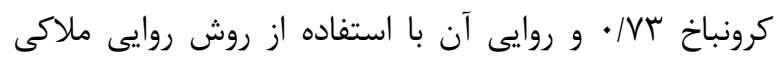

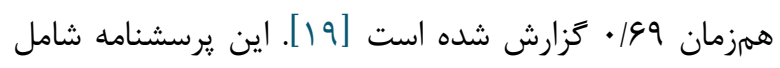

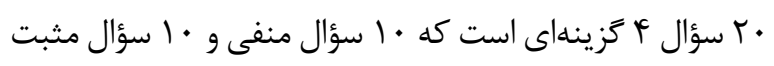

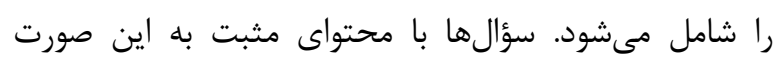

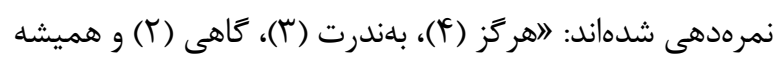

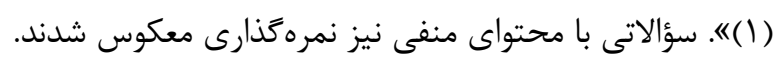

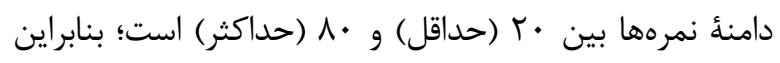

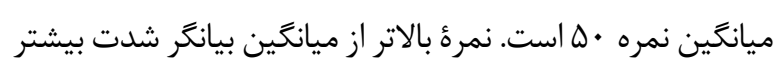

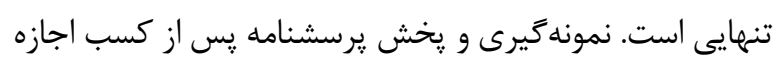

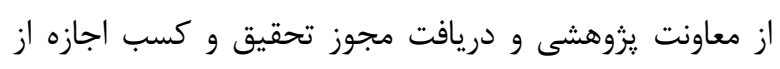

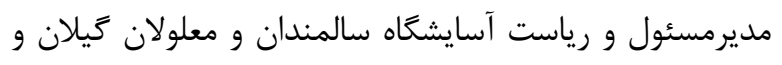

جدول ا. محتواى جلسات خاطرهَّويى

\section{موضوع جلسه}

شماره جلسه

\begin{tabular}{|c|c|}
\hline استفاده از عكسهاى مكانهاى تاريخى استان كيلان & جلسؤ 1 \\
\hline استفاده از عكسهاى اتومبيل هاى قديمى & جلسؤ ب \\
\hline استفاده از آلبوم اسكناسها و تمبرهاى قديمى & 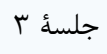 \\
\hline بخش موسيقى مربوط به خوانندگان قديمى گيلان & 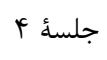 \\
\hline استفاده از عكسهاى مراسم و جشنهاى محلى كيلان & جلسؤ ه \\
\hline بخش فيلم و نمايش عكسهاى مربوط به وقايع تاريخى مههم از قبيل انقلاب & 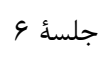 \\
\hline استفاده از عكسهاى مربوط به لباسهاى محلى استان خيلان & 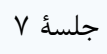 \\
\hline استفاده از عكسهاى شخصيتهاى مههم تاريخى & جلسؤ \\
\hline
\end{tabular}

بافته ها

مقايسه با ابتداى يزوهش در هر گروه با استفاده از آزمون Wilcoxon شد. سطح معنى دارى آزمونها ه • • • >

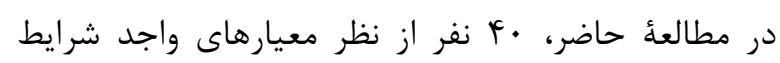

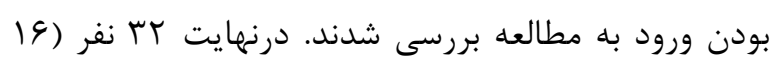

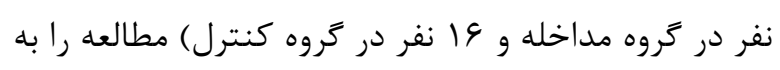

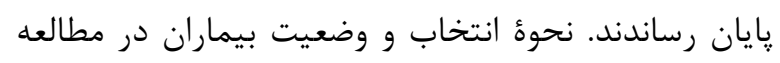
در شكل إ آمده است. رسن.
در اين مطالعه از آزمون Shapiro-Wilk براى تعيين توزيع نرماليتى استفاده شد. سيس براى مقايسٔ متغيرهاى

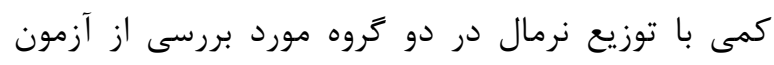
(t) Independent T-Test

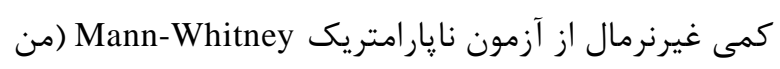
ويتنى) و براى مقايسُٔ متغيرهاى كيفى از (كاى دو) و Fisher's Exact Test (تست دقيق فيشر) استفاده شد. همجنين مقايسٔ متغيرها يس از مداخله در 

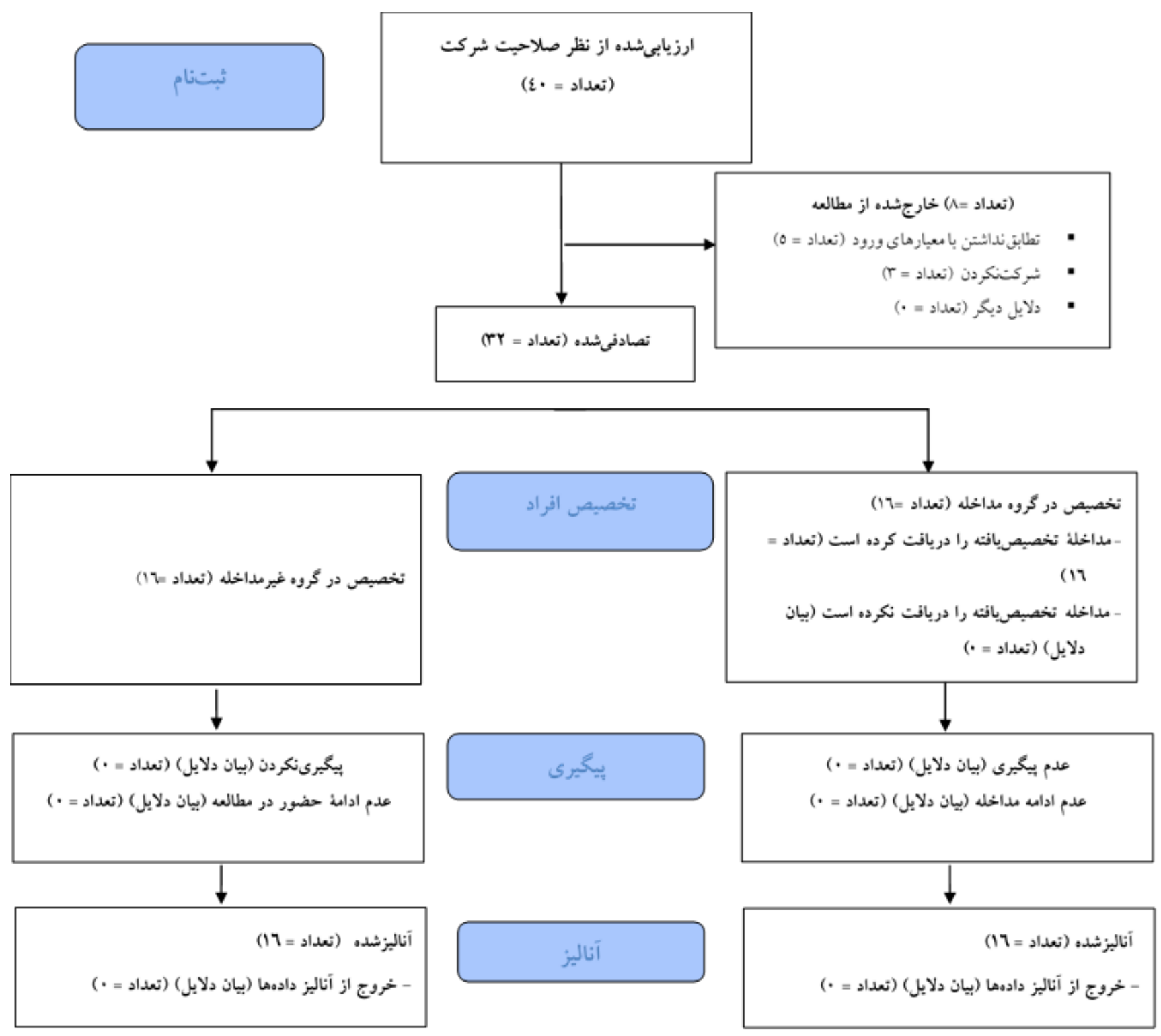

شكل ا. الكَوريتم نحوءٔ انتخاب و وضعيت بيماران در مطالعه

مشخصات دموكرافيك سالمندان مقيم آسايشعاه سالمندان و معلولان كَيلان آمده است. براساس نتايج بررسى احساس تنهايى در سالمندان مقيم

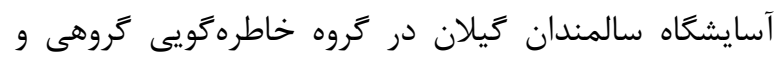

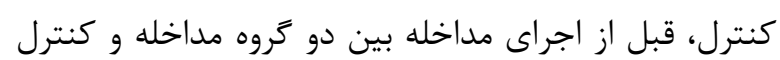

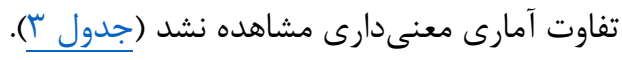

ميانكين سنى شركت كنندكان در مطالعه

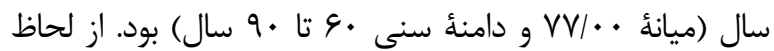

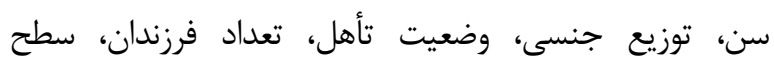

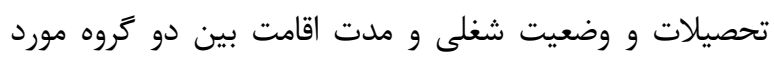

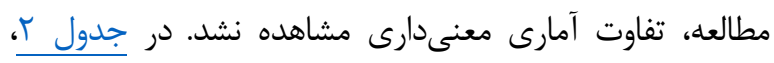




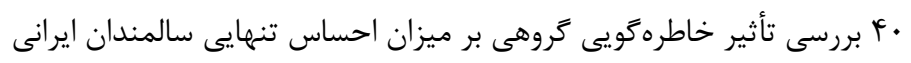

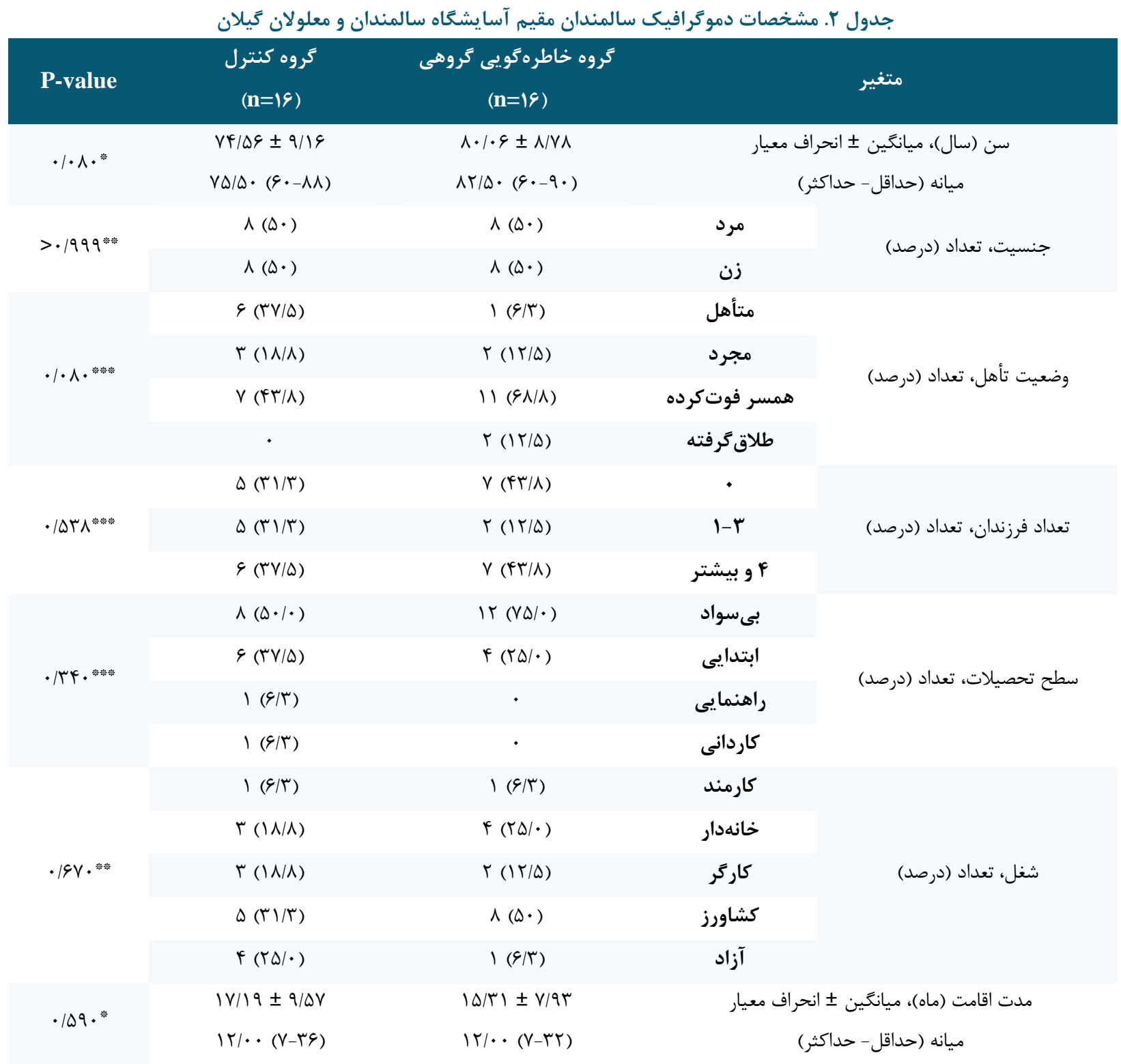

Mann Whitney Test"* Chi Square Test ${ }^{* * *} \quad$ Fisher's Exact Test ${ }^{* * * * *}$

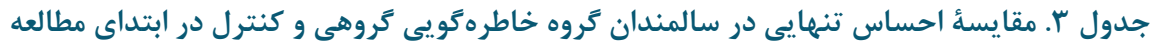

\begin{tabular}{|c|c|c|c|c|}
\hline \multirow{2}{*}{ P-value } & \multicolumn{2}{|c|}{ ميانگين 土 انحراف معيار } & \multirow{2}{*}{ دامنه نمرات } & \multirow{2}{*}{ متغير } \\
\hline & $\begin{array}{c}\text { كروه كنترل } \\
(\mathbf{n}=19)\end{array}$ & $\begin{array}{c}\text { كروه خاطرهزويى كروهى } \\
(n=19)\end{array}$ & & \\
\hline$\cdot \mid a t \Delta$ & $\begin{array}{c}\Delta \Delta / \varepsilon \Lambda \pm r / V T \\
\Delta \Delta / \Delta \cdot(\Delta \cdot / \cdot-q) / \cdot \cdot)\end{array}$ & $\begin{array}{c}\Delta \& \mid \& T \pm V / F \cdot \\
\Delta q / \Delta \cdot(\& \&|\cdots-q \varepsilon| \cdot \cdot)\end{array}$ & $r+-\Lambda$. & $\begin{array}{l}\text { احساس تنهايى ) } \\
\text { (UCLA-20) }\end{array}$ \\
\hline
\end{tabular}

Independent T-Test* 
وضعيت احساس تنهايى در سالمندان گروه خاطرهزيى

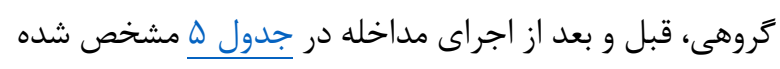

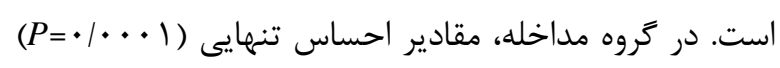

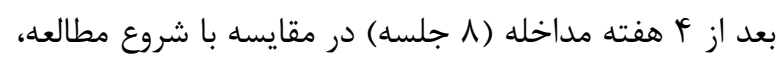
بلمطور معنى دارى كاهش داشته است.
نتايج بررسى احساس تنهايى در سالمندان مقيم آسايشگاه

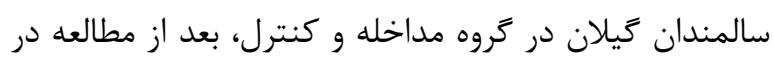

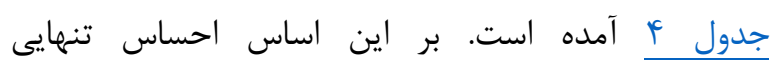

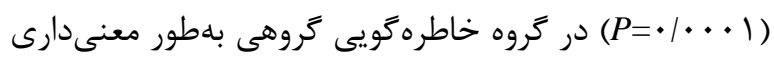

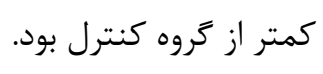

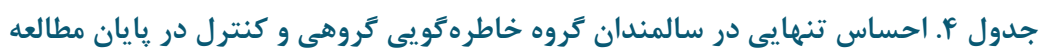

\begin{tabular}{|c|c|c|c|c|}
\hline \multirow[t]{2}{*}{ P-value } & \multicolumn{2}{|c|}{ ميانگين 土 انحراف معيار } & \multirow{2}{*}{ دامنهُ نمرات } & \multirow{2}{*}{ متغير } \\
\hline & كروه كنترل (1) & 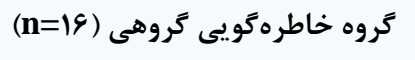 & & \\
\hline $.1 \cdots$ & $\begin{array}{c}\Delta N / \Delta \varphi \pm \Delta / r \cdot \\
\Delta q / \Delta \cdot(|c q| \cdot-q q \mid \cdot \cdot)\end{array}$ & $\begin{array}{c}F V / G \Lambda \pm N / I V \\
F Q / \Delta \cdot(\Psi G / \cdot \cdot-G \cdot / \cdot \cdot)\end{array}$ & $r+-\Lambda$. & $\begin{array}{l}\text { احساس تنهايى (UCLA-20) } \\
\text { (UCLA }\end{array}$ \\
\hline
\end{tabular}

Independent T-Test*

جدول ه. مقايسُٔ احساس تنهايیى در كروه خاطرهَّويى كَروهى قبل و بعد از اجراى مداخله

\begin{tabular}{|c|c|c|c|}
\hline \multirow[t]{2}{*}{ P-value* } & يار & & \multirow[t]{2}{*}{ متغير } \\
\hline & بعد مداخله & قبل مداخله & \\
\hline$\cdot 1 \cdot \cdot 1$ & $\begin{array}{c}F V / q \Lambda \pm \Lambda / I V \\
F \Delta / \Delta \cdot(\Psi q / \cdots-q \cdot / \cdots)\end{array}$ & $\begin{array}{c}\Delta q / q T \pm V / \Psi \cdot \\
\Delta q / \Delta \cdot(\& q \mid \cdots-q q / \cdots)\end{array}$ & احساس تنهايى (UCLA-20) \\
\hline
\end{tabular}

Paired T Test*

بر اساس نتايج بهدستآمده از بررسى احساس تنهايى در اين تفاوت از نظر آمارى معنى دار نبود. در جدول 9 احساس

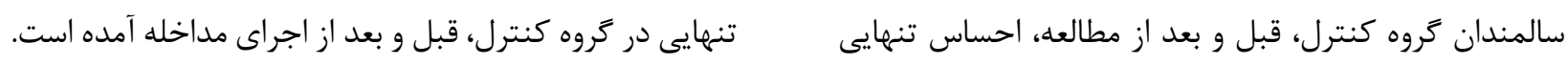

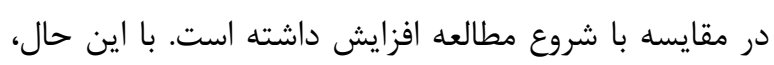

جدول 9. مقايسُٔ احساس تنهاييى در كروه كنترل قبل و بعد از اجراى مداخله

\begin{tabular}{|c|c|c|c|}
\hline \multirow{2}{*}{ "P-value } & ثر ) & & \multirow{2}{*}{ 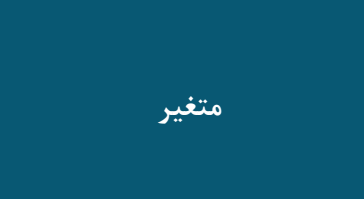 } \\
\hline & 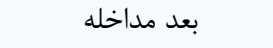 & قبل مداخله & \\
\hline$\cdot 1 \cdot r \wedge$ & $\begin{array}{c}\Delta \Lambda / \Delta \varphi \pm \Delta / r \cdot \\
\Delta q / \Delta \cdot(\mid q \varepsilon / \cdots-q \varepsilon / \cdot \cdot)\end{array}$ & $\begin{array}{c}\Delta \Delta / G \Lambda \pm r / V T \\
\Delta \Delta / \Delta \cdot(\Delta \cdot / \cdot-G \mid / \cdot \cdot)\end{array}$ & احساس تنهايى (UCLA-20) \\
\hline
\end{tabular}

Paired T Test* 
معنى دارى در افسردگى و احساس تنهايى سالمندان مشاهده

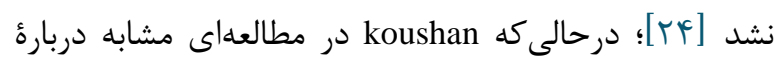

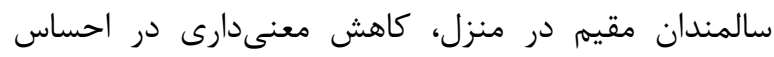

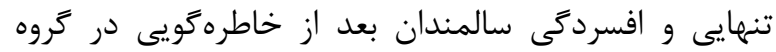
مداخله مشاهده كرد. وى معتقد است تفاوت در جامعأ بزوهش

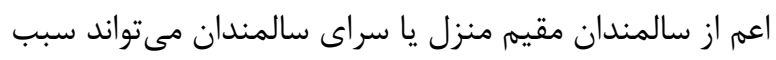

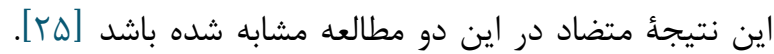
اين موضوع مىتواند با تفاوت شدت افسردگى در سالمندان مقيم منزل و مقيم سراى سالمندان ارتباط داشته باشد. مطالعه Heidari نيز نشان مي دهد، بين دو كروه از نظر احساس

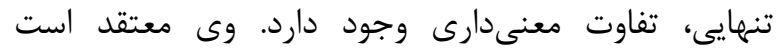

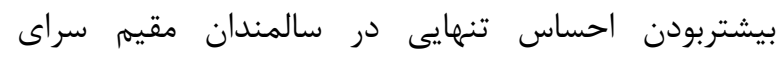

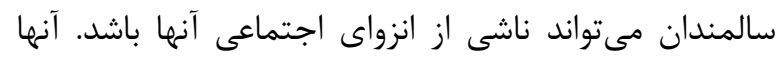

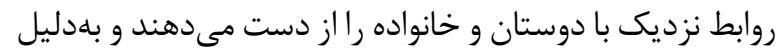

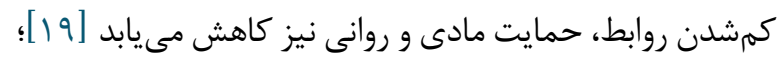

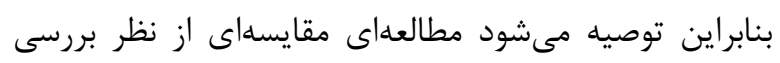

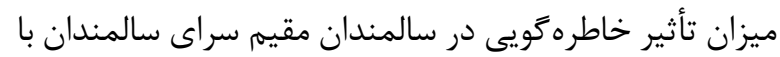

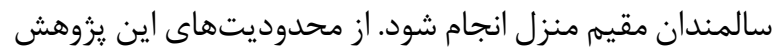

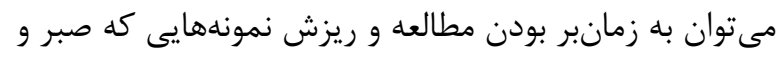

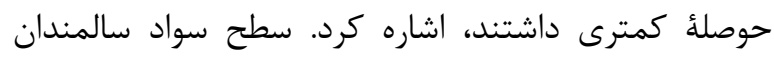
بسيار يايين و براى تحريك خاطرات امكانات محدودى دانى

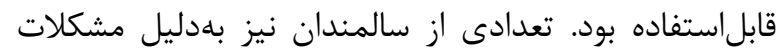

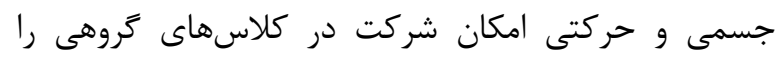
نداشتند. توصيه مىشود در مطالعات بعدى تأثير خاطرهكويى در ساير جنبههاى سلامت روان مطالعه شود.

\section{نتيجه كيرى}

خاطرهزويى گروهى بلعنوان روشى يويا و تعاملى مىتواند سبب كاهش افسردگى در سالمندان شود. در اين روش، سالمند

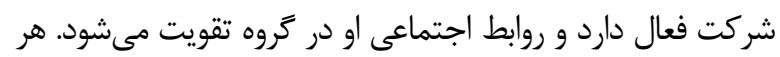

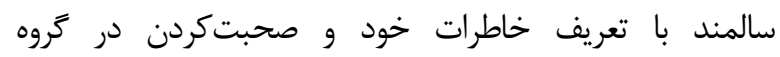

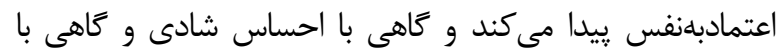

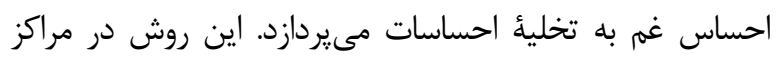

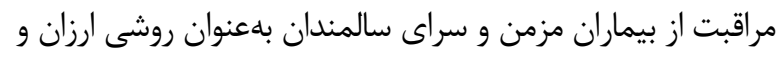
غيردارويى قابلاجراست. آموزش اين روش به خانوادهها براى توسعأ سئ

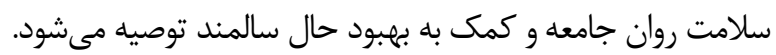

با توجه به نتايج مطالعه حاضر، خاطرهويى موجب كاهش احساس تنهايى سالمندان مقيم سراى سالمند كيلان مىشود. اين

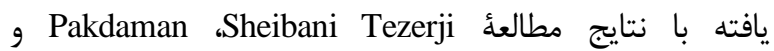
Hassanzadeh Tavakoli حجم نمونه نزديك به حجم نمونهٔ مطالعه حاضر دربارئ احساس إس

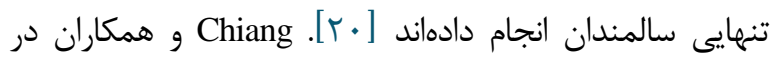

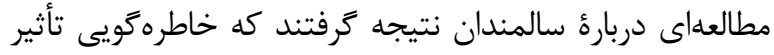
معنادارى بر كاهش احساس تنهايى سالمندان دارد. وى معتقد

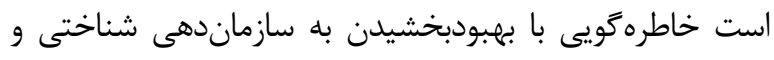

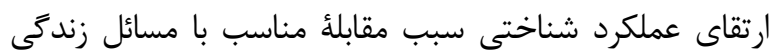
مىشود. همجنين با ارتقاى تعاملات اجتماعى و استفاده از

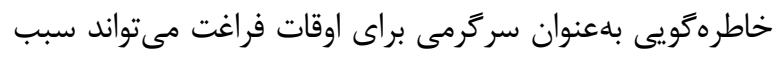

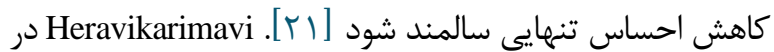
مطالعهاى كيفى، نشان داد كه بيشتر شركت كنندًان خاطرات كذشته را بهعنوان يك انتخاب براى رهايى از احساس تنهائ

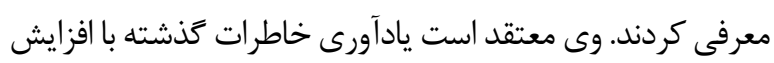

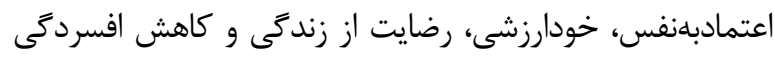
سبب افزايش تعاملات اجتماعى و عملكرد انطباقى و كاهش راهي

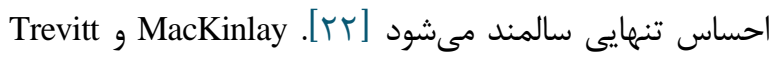
نيز نشان دادند كه مرور خاطرات موجب برطرفشدن نكرانى،

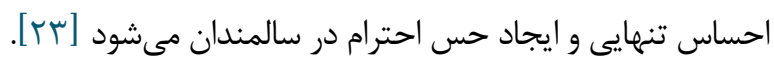
در مطالعه حاضر، تأثير خاطرهز

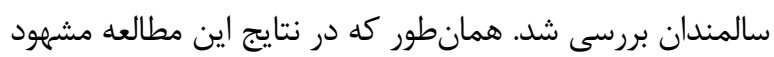
است، احساس تنهايى در سالمندان مقيم اين سراى سالمندان بالاترين نمره از ابزار مربوط را كسب كرده است. نمرة احساس

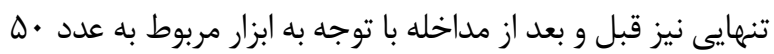
نزديك بوده كه احتمال زياد احساس تنهايى را مطرح مى كند و به احتمال زياد اين امر نشاندهنده شدت احساس تنهايى بالا در

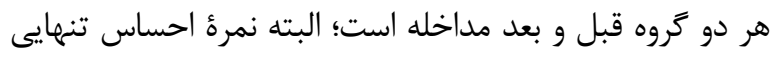
در گروه مداخله كاهش معنى دارى بعد از 1 جلسه داشته است

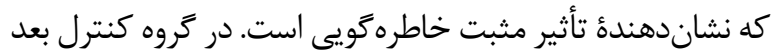

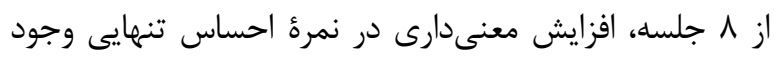

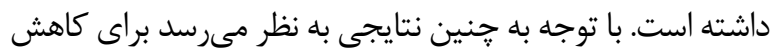
بيشتر در شدت احساس تنهايى در سالمندان مقيم سراى سالمندان، استفاده از دورههاى طولانىتر خاطرهكويى مؤثرتر واقع شود. در مطالعُ Chao مشخص شد كه بعد از مداخله تغيير 


$$
\text { منابع مالى }
$$

اين مطالعه توسط كميته اخلاق دانشعاه علوم يزشكى گيلان با كد اخلاق IR.GUMS.REC.1395.38 مورد تاييد قرار گرفته است. نويسندگان برخود لازم مى دانند از حمايت هاى معاونت تحقيقات و فناورى دانشعاه علوم يزشكى گيلان تشكر و قدردانى نمايند.

\section{References}

1. Castner J Moshfeghi G, Rezabakhsh H, Danesh E. Effectiveness of horticulture therapy on depression. Advances in Nursing \& Midwifery. 2015;24(86):2734.

2. Nabavi SH, Alipoor F, Hejazi A, Rabanie E, Rashidi W. Relationship between social support and mental health in older adults. J Mashad Univ Med Sci. 2014;57(7):841-6.

3. Nazari H, Rashedi V, Mohammadi H, Yousefi M. Relationship between cognitive status and activities of daily living among the elderly of nursing homes. Journal of Kermanshah University of Medical Sciences. 2015;18(12):744-46.

4. Sheikholeslami F, Reza Masouleh S, Khodadadi N, Yazdani MA. Loneliness and general health of elderly. Journal of Holistic nursing and midwifery. 2011;21(2):28-34.

5. Statistical Center of Iran. Calendar Statistics Gilan. Rasht(Gilan): Statistical Center of Iran; 2013. p. 97-9.

6. Riahi ME. Comparative study of the position and status of elderly people in the past and contemporary societies. Iranian Journal of Ageing. 2008;3(3\&4):1021.

7. Hawkley LC. Loneliness and social embeddedness in old age. Encyclopedia of Geropsychology. 2015 May:1-8. [DOI:10.1007/978-981-287-080-3 70-1]

8. Noghani F, Navab E, Mehran A. The Effects of Group Reminiscence Therapy on Loneliness and Spiritual Well-being among Residents of Kahrizak Nursing Home. Iran J Nurs Res. 2018;13(1):47-56. [DOI:10.21859/ijnr-13017]

9. Chiang KJ, Chu H, Chang HJ, Chung MH, Chen CH, Chiou HY, Chou KR. The effects of reminiscence therapy on psychological well-being, depression, and loneliness among the institutionalized aged. International Journal of Geriatric Psychiatry: Open J Psychiatry Allied Sci. 2010;25(4):380-8. [DOI:10.1002/gps.2350] [PMID]

10. Fakhar F, Navayinezhad S, Foroughan M. The role of group counseling with logo-therapeutic approach on the mental health of older women. Iran J Ageing. 2008;3(1):58-67.

$$
\begin{aligned}
& \text { سياسگزارى } \\
& \text { ما بدينوسيله، از تمامى اشخاصى كه با ارائه نظرات ارزشمند، } \\
& \text { ما را يارى كردند قدردانى مىشود. } \\
& \text { تعارض در منافع } \\
& \text { بين نويسندكان هيجَّونه تعارضى در منافع وجود ندارد }
\end{aligned}
$$

11. Hsieh HF, Wang JJ. Effect of reminiscence therapy on depression in older adults: a systematic review. Int $\mathbf{J}$ Nurs Stud. 2003;40(4):335-45. [DOI:10.1016/S00207489(02)00101-3]

12. Sadeghi K, Khazaie H. The comparison of efficacy pharmacotherapy and group cognitive therapy in dimensions of temperament and character of patients with major depression disorder. J Kermanshah Univ Med Sci. 2013;17(4):230-6.

13. Chao S, Liu H, Wu C, Jin S, Chu T, Huang T, Clark MJ. The effects of group reminiscence therapy on depression, self-esteem, and life satisfaction of elderly nursing home residents. J Nurs Res. 2006;14(1):36. [DOI:10.1097/01.JNR.0000387560.03823.c7] [PMID]

14. Sheykhi A, Navidian A, Keykha R, Rezaee N. Effect of reminiscence on the happiness the retired elderly members of the Islamic Republic of Iran Army. Iran J Nurs. 2019;32(119):1-1. [DOI:10.29252/ijn.32.119.1]

15. Moradinejad S, Sahbaee F, Nakavand M, Zare M. The Effect of reminiscence therapy on elderly mental health. Iran J Ageing, 2010;5(17):60-6.

16. Shellman JM, Mokel M, Hewitt N. The effects of integrative reminiscence on depressive symptoms in older African Americans. Western J Nurs Res. 2009;31(6):772-86. [DOI:10.1177/0193945909335863] [PMID]

17. Stinson CK, Kirk E. Structured reminiscence: an intervention to decrease depression and increase selftranscendence in older women. J Clin Nursing. 2006;15(2):208-18. 2702.2006.01292.x] [PMID]

18. Department of Social Welfare of Gilan. Welfare Director of Gilan, Gilan with $11.7 \%$ of the elderly, the oldest in the country[Internet]. Rasht: Department of Social Welfare of Gilan; [updated 2015 October 11th; cited 2015]. Available from: http://www.behzistyguilan.ir/showNews.aspx ?id=1650.

19. Heidari M, Ghodusi Borujeni M, Naseh L. Comparison of self-efficacy and loneliness between community-dwelling \& institutionalized older people. Iran J Ageing. 2016;11(1):142-51. [DOI:10.21859/sija-1101142]

$$
\text { مجله مراقبت يرستارى و مامايى ابنسينا }
$$


Fץ برسى تأثير خاطرهوَيى كروهى بر ميزان احساس تنهايى سالمندان ايرانى

20. Sheibani Tezerji,Sh. Pakdaman, M.R. Hassanzadeh Tavakolithe effect of reminiscence on depression and loneliness in elderly. J Appl Psychol.20101(13):2639.

21. Chiang KJ, Chu H, Chang HJ, Chung MH, Chen CH, Chiou HY, Chou KR. The effects of reminiscence therapy on psychological well-being, depression, and loneliness among the institutionalized aged. International Journal of Geriatric Psychiatry: A journal of the psychiatry of late life and allied sciences. 2010;25(4):380-8. [DOI:10.1002/gps.2350] [PMID]

22. Heravikarimavi M, Anoushe M, Froughan M, Sheikhi M, Hajizade E. Seyed bagher madah M, Mohammadi E, Ahmadi F. Explain the phenomenon of loneliness around the elderly: a qualitative studyA phenomenological. salmand. 2007;2(6):410-20.

23. MacKinlay E, Trevitt C. Living in aged care: Using spiritual reminiscence to enhance meaning in life for those with dementia. International journal of mental health nursing. 2010;19(6):394-401. [DOI:10.1111/j.1447-0349.2010.00684.x] [PMID]

24. Chao S, Liu H, Wu C, Jin S, Chu T, Huang T, Clark MJ. The effects of group reminiscence therapy on depression, self-esteem, and life satisfaction of elderly nursing home residents. J Nurs Res. 2006; 14(1):3645. [DOI:10.1097/01.JNR.0000387560.03823.c7] [PMID]

25. koushan $\mathrm{m}$, mollashahi $\mathrm{z}$, delbari a, rakhshani mh. the effects of group reminiscence on loneliness in elders. J sabzevar Uni of Med Sci. 2014;21(4):569-77. 